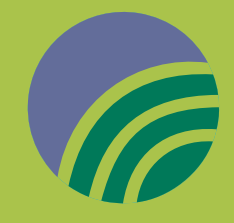

\title{
MRS and SMM hold
}

International Materials
Research Congress 2014
in Cancún

\author{
www.mrs-mexico.org.mx/imrc2014 \\ www.mrs.org/meeting-scene
}

\section{The XXIII International Materials 1 Research Congress (IMRC)} 2014, chaired by Armando Salinas Rodríguez, President of the Sociedad Mexicana de Materiales (SMM), of Cinvestav; Heberto Balmori Ramirez, Instituto Politécnico Nacional (Mexico); Marcela R. Beltrán, Universidad Nacional Autónoma de México; Kenneth Adrian Dawson, University College Dublin; and Nagarajan Valanoor, University of New South Wales, was held in Cancún, Mexico, August 17-21. This annual international meeting is a joint effort of the Materials Research Society (MRS) and SMM.

During the opening ceremony Rodríguez acknowledged the Meeting Chairs, as well as Márgara Smith, who has been a leader of the organizing committee for the IMRC for many years, and MRS President Tia Benson Tolle for their hard work and dedication. The result of their efforts has been a 7\% growth in abstracts submitted over last year's Congress.
Mihail C. Roco, National Science Foundation and National Nanotechnology Initiative, gave the first Plenary Lecture of the Congress. Roco took a long-term view in evaluating the current and future status of nanotechnology around the globe. "It takes 30 years to go from a scientific curiosity, the way nanotechnology was in the year 2000 , to immersion in society," he said, adding that nanomanufacturing "could eventually match or outstrip the digital revolution. We are still at the beginning of nanotechnology," Roco said.

The second Plenary Lecture was given by Lai-Sheng Wang, Brown University, titled "From Planar Boron Clusters to Borophene and All-Boron Fullerenes." While boron analogues to graphene were predicted years ago based on the element's high melting point and closeness to carbon in the periodic table, the realization has not been easy. Part of the problem is that elemental boron occurs in clusters of icosahedral $\mathrm{B}_{12}$ cages, not in flat sheets like graphene. "So the Scotch tape method that worked for graphene is out of the question," said Wang.

On the third day of the Congress, Sergei V. Kalanin of Oak Ridge National Laboratory gave attendees a thorough background regarding electrochemistry on the nano and atomic levels in his Plenary Lecture. He believes that the 21st century will be dominated by electoral control of matter. "Right now, our capacity to use electrical currents to shape matter is relatively limited," he said.

Douglas Osheroff, 1996 Nobel Laureate in Physics, gave a Science Luncheon Talk on advances in science, outlining five relevant research strategies: (1) use the best instrumentation available; (2) don't reinvent technology_-borrow it; (3) look into unexplored regions of the physical landscape; (4) realize that failure might be an invitation to try something new; and (5) be aware of new, subtle, and unexplained behavior.

At the symposia, grad students, postdocs, and professors discussed their latest work. A special session on establishing new University Chapters sponsored jointly by SMM and MRS drew a large crowd of students in the afternoon, as they learned about the challenges, opportunities, and benefits of becoming part of this worldwide movement. Researchers also showed their work in poster form.

A large gathering of students from all over Mexico and South America assembled on Tuesday afternoon to learn how they might start an MRS University

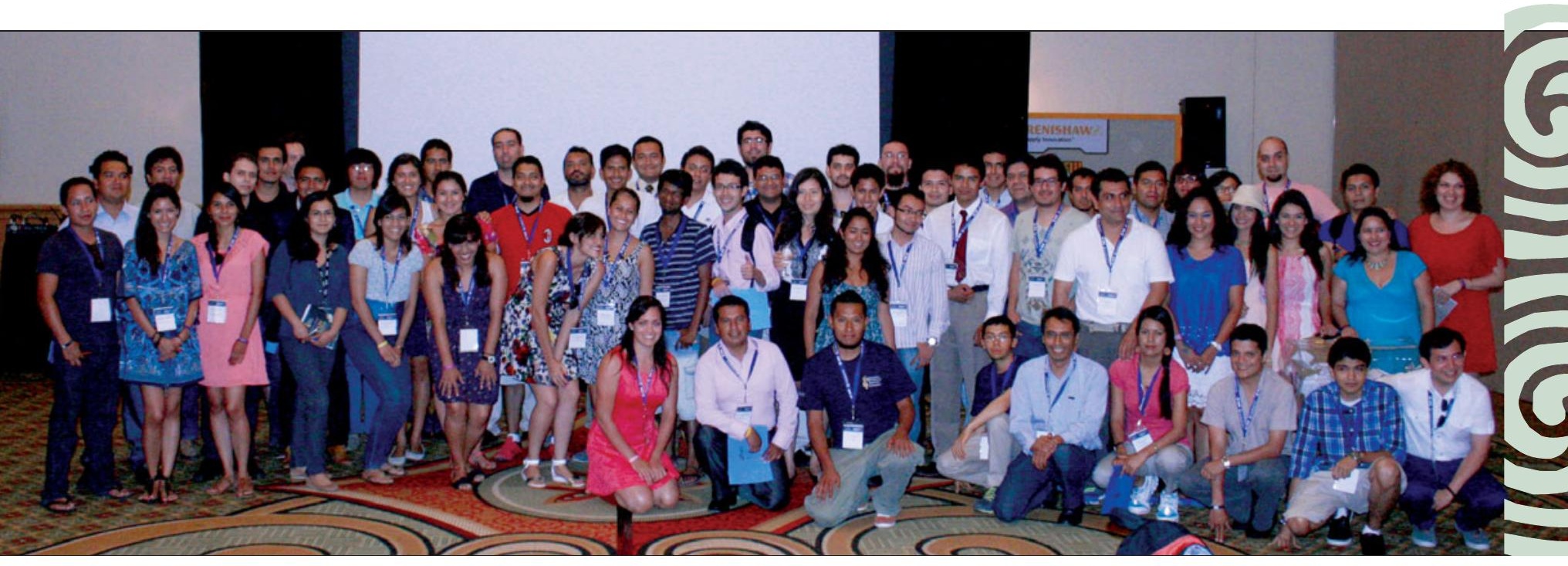



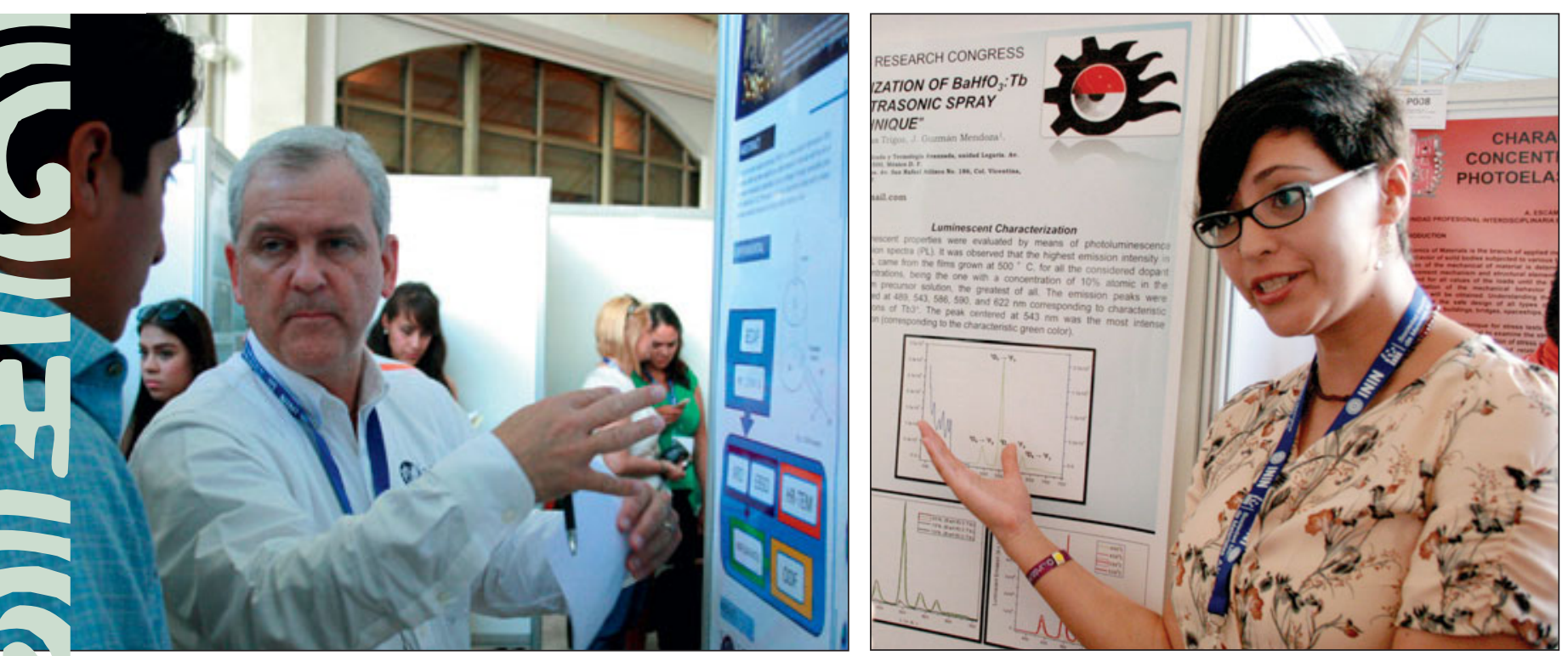

Chapter at their institutions, including how to apply for official Chapter status, how to organize a Chapter, and what activities and benefits go along with University Chapter membership. Benefits include funding to attend meetings like the IMRC, a chance to establish leadership credentials by being an officer of the Chapter, and learning from one's fellow Chapter members and invited guest speakers through organized events.

Rodríguez noted that there are already four University Chapters established in Mexico, and he would like to see this number reach ten by the time his term is complete after two years. "We are hopeful that in a few years, you will be standing up here and leading this meeting, encouraging new students to join," he said.

MRS President Tia Benson Tolle, SMM Vice President Claudia Gutiérrez Wing, MRS Immediate Past President Orlando Auciello, and MRS Executive Director Todd Osman joined in the discussion of the possibilities presented by University Chapter membership. There are already more than 85 MRS University Chapters worldwide, and Mexico and South America could add a significant number of new Chapters with their large student populations. The speakers emphasized that they were open to new ideas about activities and initiatives University Chapters could plan, and the students responded with suggestions such as competitions and cooperation between Chapters.

Wednesday featured another Plenary Lecture, by Anthony Rollett of Carnegie Mellon University on three-dimensional (3D) characterization and modeling of materials, a field that is growing rapidly with the increase in speed and memory of computers. Rollett gave an overview of the developments in 3D characterization and modeling that have been made possible by high-energy x-rays from synchrotrons, open access (free) software for analyzing the data collected from these high-energy $x$-rays when they encounter materials, and the development of "image-based" simulation codes that free computational scientists from the mesh-based models of finite element analysis.

At the Gala Dinner, Rodríguez and other IMRC organizers announced the winners of the Best Poster Awards for the week. The three best posters will be displayed at the 2015 MRS Spring Meeting in San Francisco. The technical symposia throughout the conference featured talks on several aspects of materials science by some of the finest researchers in the world. In-depth coverage of the plenary sessions, technical talks, and other meeting events is available at www.mrs.org/meeting-scene.

\section{Sponsors of the XXIII International Materials Research Congress (IMRC) 2014}

\section{Principal Sponsors:}

Consejo Nacional de Ciencia y Tecnología (CONACYT)

Centro de Investigación y de Estudios Avanzados del IPN (Cinvestav)

\section{Symposia Sponsors:}

\section{American Elements}

Anasys Instruments Corp.

Bruker

Centro de Investigaciones en Optica, A.C.

Consejo Nacional de Ciencia y Tecnología (CONACYT)

Coordinación de la Investigación Científica, UNAM

Instituto de Investigaciones en Materiales, UNAM

Instituto Mexicano de Tecnología del Agua (IMTA)

Instituto Nacional de Investigaciones Nucleares (ININ)

Intercovamex

Polymer Source

Royal Society of Chemistry-Journals of Materials Chemistry A and C

Universidad Autónoma de San Luis Potosí

Universidad de La Ciénega del Estado de Michoacán de Ocampo

Wiley-VCH 